\title{
Statistical Modelling of the Spring Back Behavior for Bending of V-Shaped Parts from Common Sheet Metal
}

\author{
Drăghici Constantin \\ Department of Theory of mechanisms and a robot \\ University Politehnica of Bucharest \\ Bucharest, Romania \\ ctin_draghici@yahoo.com
}

\begin{abstract}
This paper presents the experimental program and measured results, obtained model, statistic analysis and some graphics for springback angle of common sheet metal. There were considered three bending parameters: bending's angle, sheet's thickness and radius' punch. The obtained model is interactive second order polynomial ones. There are also presented some observations and a few relevant conclusions regarding the obtained results.
\end{abstract}

Keywords - statistic modeling; V - banding; spring back behavior; smallest squares method

\section{INTRODUCTION}

Spring back, defined as difference between obtained values of V-bending angle of a workpiece, and the initial angle of bending, is one of the major causes which appears to fabrication of $\mathrm{V}$-shaped parts. This is a geometrical defect that occurs on the drawn part after the removing all the stamping tools, and it is caused by elastic strain recovery of the material. For this reason, the value of initial bending angle must be modified, increasing or decreasing with the value of spring back angle.

Calculating the value of spring back angle is indicated in specific literature taking in account empirical solution or graphics.

For V-bending one can calculated the spring back angle using the following relation [1], [2]:

$$
\Delta \alpha=\operatorname{arctg}\left(0,375 \frac{L_{p 1}}{k \cdot g} \cdot \frac{R_{p}}{E}\right)
$$

where: $\mathrm{k}$ - coefficient as function of the position of neutral layer, $\mathrm{L}_{\mathrm{p} 1}$ - distance between the filled radius of bending plate, $\mathrm{g}$ - thickness' band, E - Youngs' modulus.

\section{THE MOdEL AND THE EXPERIMENTAL DATA USED}

For statistic modeling of spring back as function of three parameters, respectively, bend angle, thickness and punch

The work has been funded by the Sectoral Operational Programme Human Resources Development 2007-2013 of the Ministry of European Funds through the Financial Agreement POSDRU/187/1.5/S/155536. radius, was used an interactive second order polynomial model with eleven coefficients as:

$$
\begin{aligned}
\Delta \alpha & =b_{0}+b_{1} \cdot \alpha_{o}+b_{2} \cdot g+b_{3} \cdot r+b_{11} \cdot \alpha_{0}^{2}+ \\
& +b_{22} \cdot g^{2}+b_{33} \cdot r^{2}+b_{12} \cdot \alpha_{0} \cdot g+b_{13} \cdot \alpha_{0} \cdot r+ \\
& +b_{23} \cdot g \cdot r+b_{123} \cdot \alpha_{0} \cdot g \cdot r
\end{aligned}
$$

where: $\alpha_{0}$ - bend angle, Degree; g - thickness, mm; $r$ initial bend radius.

Experimental data for determining the coefficients of the model (2) are ones corresponding to a composite orthogonal factorial program with central points, of $2^{3}$ type with three independent variables, varied to five levels of variation as shown in Table I, based on the information published by Box and Wilson [4].

TABLE I. NATURAL INDEPENDENT VARIABLES. VARIATION FIELDS AND LEVELS.

\begin{tabular}{|c|c|c|c|c|c|}
\hline Variable & \multicolumn{5}{|c|}{ Variation levels, in natural units } \\
\hline $\begin{array}{c}\text { Bend angle, } \\
\alpha_{0} \text { (degree) }\end{array}$ & 85 & 57.57 & 100 & 115 & 142.42 \\
\hline $\begin{array}{c}\text { Thickness, } \\
\text { g (mm) }\end{array}$ & 0,5 & 1 & 1,5 & 2 & 2,5 \\
\hline $\begin{array}{c}\text { punch radius, } \\
\text { r (mm) }\end{array}$ & 0,3 & 3,5 & 5,25 & 7 & 10,2 \\
\hline
\end{tabular}

The program consisted of three series of experiments as shown in Table II. The first series consisted of 9 experiments (15 to 23) which were replicated in the centre of the experimental space. The replication of experiments provided an estimate of the experimental error from which confidence intervals for the parameters were evaluated. The second series consisted of 8 experiments (1 to 8 ) represented the angular points given by a full factorial program with 23 experiences and were represented geometrically by the corners of a 3D cube encasing the experimental space. The third series consisted of 6 experiments represented the axial points ( 9 to 14). These experimental points were placed on the coordinate axes at a certain distance from central points. 
TABLE II. EXPERIMENTAl PRogram AND Results of Modelled Characteristic.

\begin{tabular}{|c|c|c|c|c|c|c|c|c|c|c|}
\hline \multirow{3}{*}{$\begin{array}{l}\text { Exp. } \\
\text { no. }\end{array}$} & \multirow{2}{*}{\multicolumn{3}{|c|}{ Variables }} & \multicolumn{3}{|c|}{ Answers } & \multirow{3}{*}{\multicolumn{3}{|c|}{$\begin{array}{c}\text { Confidential } \\
\text { intervals } 95 \%\end{array}$}} & \multirow{3}{*}{$\begin{array}{l}\text { Error } \\
\Delta(\%)\end{array}$} \\
\hline & & & & \multicolumn{2}{|c|}{ Measured } & \multirow{2}{*}{$\begin{array}{c}\text { Calculated } \\
\Delta \tilde{\alpha} \\
\text { [grade] }\end{array}$} & & & & \\
\hline & $\begin{array}{c}\alpha_{0} \\
\text { [grade] }\end{array}$ & $\begin{array}{c}\mathrm{g} \\
{[\mathrm{mm}]}\end{array}$ & $\begin{array}{c}\mathbf{r} \\
{[\mathrm{mm}]}\end{array}$ & $\begin{array}{c}\alpha \\
\text { [grade] }\end{array}$ & $\begin{array}{c}\Delta \alpha \\
\text { [grade] }\end{array}$ & & & & & \\
\hline 1 & 85 & 1 & 3.5 & 83.66666 & -1.33334 & 1.9823 & 2.6226 & $\div$ & 1.3420 & -1.67262 \\
\hline 2 & 115 & 1 & 3.5 & 114.25 & -0.75 & 2.5793 & 3.2196 & $\div$ & 1.9390 & -1.29078 \\
\hline 3 & 85 & 2 & 3.5 & 82.75 & -2.25 & 0.0577 & 0.6980 & $\div$ & -0.5826 & -39.9948 \\
\hline 4 & 115 & 2 & 3.5 & 108.3 & -6.7 & -4.3793 & -3.7390 & $\div$ & -5.0196 & 0.529925 \\
\hline 5 & 85 & 1 & 7 & 86.73333 & 1.73333 & 4.0875 & 4.7278 & $\div$ & 3.4472 & -0.57594 \\
\hline 6 & 115 & 1 & 7 & 114.9833 & -0.0167 & 2.3535 & 2.9938 & $\div$ & 1.7132 & -1.0071 \\
\hline 7 & 85 & 2 & 7 & 84.86666 & -0.13334 & 1.2102 & 1.8505 & $\div$ & 0.5699 & -1.11018 \\
\hline 8 & 115 & 2 & 7 & 115.8333 & 0.8333 & 2.1912 & 2.8315 & $\div$ & 1.5509 & -0.61971 \\
\hline 9 & 57.57388 & 1.5 & 5.25 & 60.1 & 2.52612 & 1.3260 & 2.0201 & $\div$ & 0.6319 & 0.905068 \\
\hline 10 & 142.42611 & 1.5 & 5.25 & 142.0333 & -0.39281 & -1.9217 & -1.2276 & $\div$ & -2.6158 & -0.79559 \\
\hline 11 & 100 & 0.5 & 5.25 & 110.1167 & 10.1167 & 6.5453 & 7.1759 & $\div$ & 5.9147 & 0.545643 \\
\hline 12 & 100 & 2.5 & 5.25 & 102.15 & 2.15 & 0.5839 & 1.2145 & $\div$ & -0.0467 & 2.682137 \\
\hline 13 & 100 & 1.5 & 0.3 & 99.48333 & -0.51667 & -2.5529 & -1.8588 & $\div$ & -3.2470 & -0.79761 \\
\hline 14 & 100 & 1.5 & 10.2 & 104.8833 & 4.8833 & 4.2375 & 4.9316 & $\div$ & 3.5434 & 0.152401 \\
\hline 15 & 100 & 1.5 & 5.25 & 102.05 & 1.39997 & 0.6022 & 0.8402 & $\div$ & 0.3642 & 1.324759 \\
\hline 16 & 100 & 1.5 & 5.25 & 101.7833 & 2.16664 & 0.6022 & 0.8402 & $\div$ & 0.3642 & 2.597874 \\
\hline 17 & 100 & 1.5 & 5.25 & 101.4167 & 1.8333 & 0.6022 & 0.8402 & $\div$ & 0.3642 & 2.044337 \\
\hline 18 & 100 & 1.5 & 5.25 & 102.1167 & 2.29997 & 0.6022 & 0.8402 & $\div$ & 0.3642 & 2.819279 \\
\hline 19 & 100 & 1.5 & 5.25 & 101.4667 & 1.8333 & 0.6022 & 0.8402 & $\div$ & 0.3642 & 2.044337 \\
\hline 20 & 100 & 1.5 & 5.25 & 101.6667 & 1.04997 & 0.6022 & 0.8402 & $\div$ & 0.3642 & 0.743557 \\
\hline 21 & 100 & 1.5 & 5.25 & 101.9667 & 2.09997 & 0.6022 & 0.8402 & $\div$ & 0.3642 & 2.487164 \\
\hline 22 & 100 & 1.5 & 5.25 & 102.0833 & 2.08333 & 0.6022 & 0.8402 & $\div$ & 0.3642 & 2.459532 \\
\hline 23 & 100 & 1.5 & 5.25 & 101.4833 & 1.49997 & 0.6022 & 0.840 & $\div$ & 0.3642 & 1.490817 \\
\hline
\end{tabular}

\section{MATERIAL AND PROCEDURE IN EXPERIMENTS}

The experiences were carried out in the Cold Pressing Laboratory of the Manufacturing Department, in POLITEHNICA University of Bucharest. The experimental stand used a dynamometric die for statistical modeling of bending features for $\mathrm{V}$-shaped parts [4] having the bend angle, $\alpha$, within $57^{\circ} \div 142^{\circ}$ and using a workpiece with thickness, $\mathrm{g}$, between $2.5 \div 3.5 \mathrm{~mm}$.

The material used for the experiments is a low carbon type, A3, STAS 9485 steel bands with $\mathrm{Rm}=(333 \div 408) \mathrm{N} / \mathrm{mm}^{2}$, which is frequently used in industry.

Fig. 1 shows a sketch of the bending test and Table II gives more information regarding the test conditions.

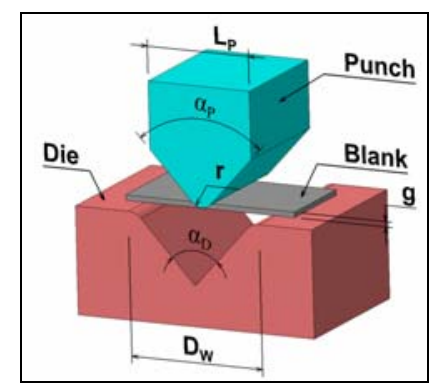

Fig. 1. Sketch of the bending test. where:

Lp - punch width, (mm); r - punch radius, $(\mathrm{mm}) ; \alpha_{P}-$ punch angle, (degrees); $\mathrm{D}_{\mathrm{W}}$ - distance between material supports, $(\mathrm{mm}) ; \alpha_{\mathrm{D}}$ - die angle, (degrees); $\mathrm{g}$ - thickness, $(\mathrm{mm})$;

For bending tests, the following actions are made:

- aligning the die and punch in the press machine;

- placing the part on the die and bringing the punch down far enough to just touch the part

- punch moves down with a constant speed and bends the blank;

- punch moves up and the resulted part is replaced

- the resulted bend angle, $\alpha$, is measured with the support of a laboratory microscope.

The sketch of the sample used in the test is shown in Fig.2. The length and width of the sheet metal sample was maintained constant at $50 \mathrm{~mm}$ and $25 \mathrm{~mm}$.

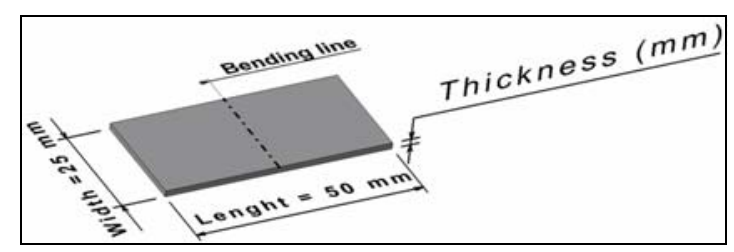

Fig. 2. Schematic of the sample. 


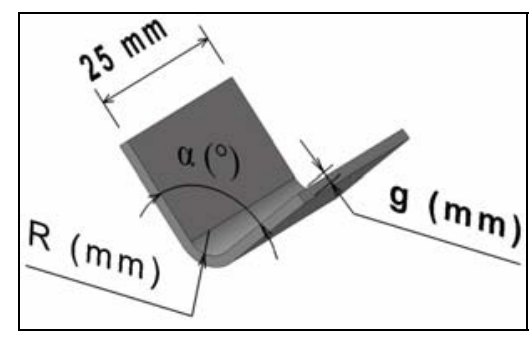

Fig. 3. Sketch of the bend part and its characteristics.

Fig. 3 shows a sketch of the resulted part after bending and its characteristics.

where:

$\alpha$ - part angle after springback occurs, (degrees)

$\mathrm{R}$ - part radius after springback occurs, $(\mathrm{mm})$

$\mathrm{g}$ - thickness, $(\mathrm{mm})$

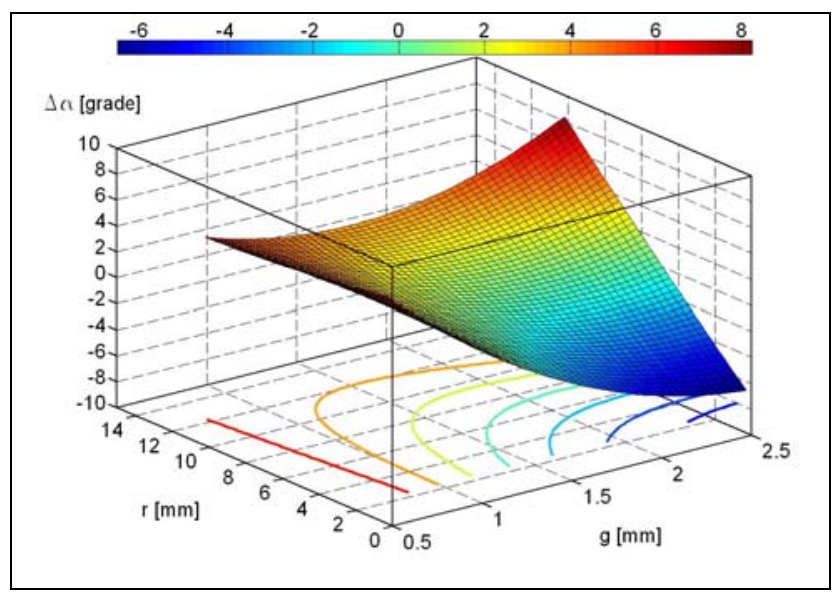

a) $\mathrm{g},(\mathrm{mm})$ and $\mathrm{r},(\mathrm{mm})$ with $\alpha=100$ (degrees).

\section{OBtAINED MOdEL AND ITS STATISTIC ANALISYS}

Using measured answers of each experience (see Table I) and the smallest squares method there were determined all model coefficients so that, there was obtained the following relation:

$$
\begin{aligned}
\Delta \alpha= & -42.3882+0.6237 \cdot \alpha_{O}+26.3594 \cdot g+8.9368 \cdot r- \\
& -0.0005 \cdot \alpha_{0}^{2}+2.9624 \cdot g^{2}+0.0098 \cdot r^{2}-0.4261 \cdot \alpha_{0} \cdot g- \\
& -0.096 \cdot \alpha_{0} \cdot r-6.5452 \cdot g \cdot r+0.0738 \cdot \alpha_{0} \cdot g \cdot r
\end{aligned}
$$

where: $\Delta \alpha$ - springback angle, (degrees); $\alpha_{0}$ - bend angle, (degrees); $\mathrm{g}$ - thickness, $(\mathrm{mm}) ; \mathrm{r}$ - initial bend radius, $(\mathrm{mm})$.

The 3D graphics for relationships between the springback angle, and the three mentioned parameters are shown in Fig. 3. In these graphics there was considered, one after the other, the relationship between the measured characteristic and two of the parameters, the third one being at the medium value of its variation field.

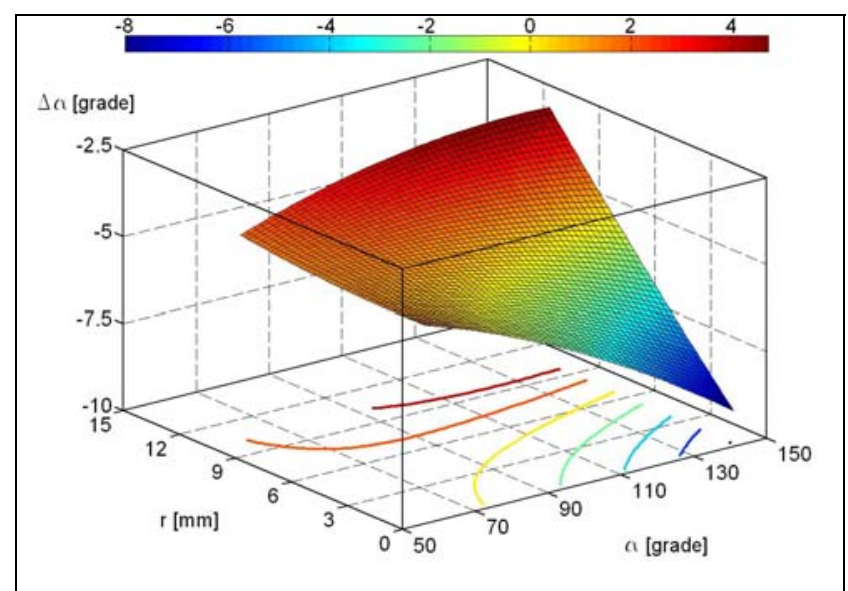

b) $\mathrm{g},(\mathrm{mm})$ and $\alpha$, (degrees) with $\mathrm{r}=5.25(\mathrm{~mm})$

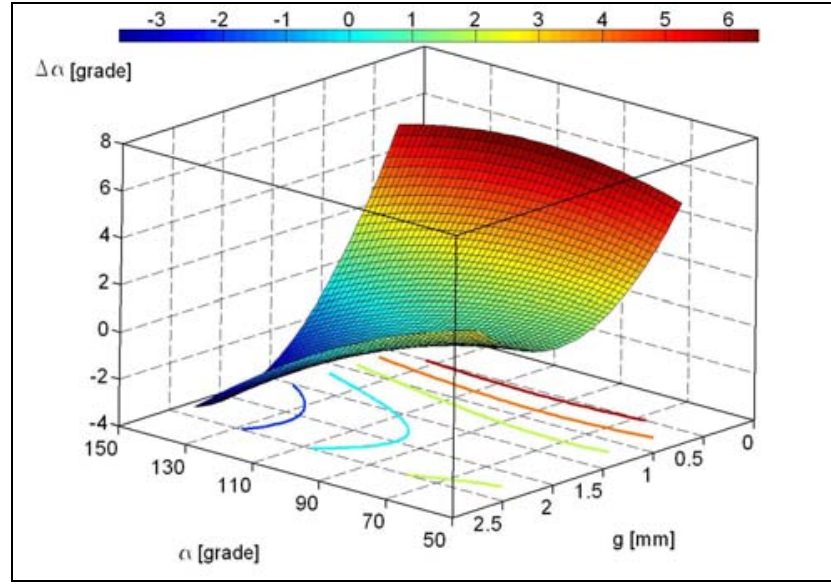

c) $\alpha$ (degrees) and $\mathrm{r}(\mathrm{mm})$ with $\mathrm{g}=1.5(\mathrm{~mm})$

Fig. 4. Graphics of spring back variation, $\Delta \alpha$, as funtion of 
Checking the model's adequacy is presented in Table III and coefficients' significance in Table IV. The 95\% confidence intervals for model predicted answers and the predictive errors, $\Delta$, are shown in Table 2. Statistical analysis was performed with natural variables model (Table II).

TABLE III. CHECKING Model's ADEQUACY.

\begin{tabular}{|c|c|}
\hline Dispersion & Values \\
\hline $\mathrm{SP}_{\mathrm{rz}}=Y^{\prime} Y-B^{\prime}\left(X^{\prime} X\right)$ & 85.234 \\
\hline $\mathrm{f}_{\mathrm{rz}}=\mathrm{n}-\mathrm{m}-1$ & 12 \\
\hline $\mathrm{PM}_{\mathrm{rz}}=\mathrm{SP}_{\mathrm{rz}} / \mathrm{f}_{\mathrm{rz}}$ & 7.1032 \\
\hline $\mathrm{SP}_{\mathrm{er}}=(Y-\bar{Y})^{\prime}(Y-\bar{Y})$ & 1.369 \\
\hline $\mathrm{f}_{\mathrm{er}}=\mathrm{n} / 2$ & 8 \\
\hline $\mathrm{PM}_{\mathrm{er}}=\mathrm{SP}_{\mathrm{er}} / \mathrm{f}_{\mathrm{er}}$ & 0.1711 \\
\hline $\mathrm{SP}_{\mathrm{in}}=\mathrm{SP}_{\mathrm{rz}}-\mathrm{SP}_{\mathrm{er}}$ & 83.8694 \\
\hline $\mathrm{f}_{\mathrm{in}}=(\mathrm{n} / 2)-\mathrm{m}-1$ & 4 \\
\hline $\mathrm{PM}_{\mathrm{in}}=\mathrm{SP}_{\mathrm{in}} / \mathrm{f}_{\mathrm{in}}$ & 22.9674 \\
\hline $\mathrm{F}_{\mathrm{ci}}=\mathrm{PM}_{\mathrm{in}} / \mathrm{PM}_{\mathrm{er}}$ & 122.5294 \\
\hline$F_{T}\left(f_{\mathrm{in}}, f_{e r}, 95 \%\right)$ & 3.84 \\
\hline $\mathrm{F}_{\mathrm{ci}}<\mathrm{F}_{\mathrm{T}}$ & inadecvat \\
\hline
\end{tabular}

TABLE IV. CHECKING COEFFICIENTS' SigNIFICANCE

\begin{tabular}{|c|c|c|c|c|c|}
\hline \multirow{2}{*}{ Coefficient } & \multirow{3}{*}{$\mathrm{PM}_{\mathrm{bi}}$} & \multirow{2}{*}{$\mathrm{F}_{\mathrm{cs}}$} & \multicolumn{2}{c|}{$F_{T[1 ; 12 ;(1-\alpha) 100]}$} \\
\cline { 5 - 6 } & & & 0.05 & 0.01 \\
\cline { 5 - 6 } & & & 4.84 & 9.33 \\
\hline Symbol & Value & & & $\sqrt{ }$ & $\sqrt{ }$ \\
\hline $\mathrm{b}_{0}$ & -42.3882 & -1119.7 & -6544 & $\sqrt{ }$ & $\sqrt{ }$ \\
\hline $\mathrm{b}_{1}$ & 0.6237 & 1526.8 & 8922 & $\sqrt{ }$ & $\sqrt{ }$ \\
\hline $\mathrm{b}_{2}$ & 26.3594 & 0730.6 & 4269 & $\sqrt{ }$ & $\sqrt{ }$ \\
\hline $\mathrm{b}_{3}$ & 8.9308 & 1687.5 & 9861 & $\sqrt{ }$ & $\sqrt{ }$ \\
\hline $\mathrm{b}_{11}$ & -0.0005 & -0110.8 & -647 & $\sqrt{ }$ & $\sqrt{ }$ \\
\hline $\mathrm{b}_{22}$ & 2.9624 & 0100.2 & 586 & $\sqrt{ }$ & $\sqrt{ }$ \\
\hline $\mathrm{b}_{33}$ & 0.0098 & 0013.1 & 76 & $\sqrt{ }$ & $\sqrt{ }$ \\
\hline $\mathrm{b}_{12}$ & -0.4261 & -1049.9 & -6135 & $\sqrt{ }$ & $\sqrt{ }$ \\
\hline $\mathrm{b}_{13}$ & -0.0960 & -1724.7 & -10079 & $\sqrt{ }$ & $\sqrt{ }$ \\
\hline $\mathrm{b}_{23}$ & -6.5452 & -1479.4 & -8645 & $\sqrt{ }$ & $\sqrt{ }$ \\
\hline $\mathrm{b}_{123}$ & 0.0738 & 1565.5 & 9149 & $\sqrt{ }$ & $\sqrt{ }$ \\
\hline
\end{tabular}

\section{RESULTS AND DISCUSSION}

The model has proven to be inadequate, may be because theirs incapacity of accurate reproduction of experimental data, pointed out by the values of residual medium square much higher than the ones of the experimental error. May be a similar model with natural variables being replaced by theirs logarithms would improve reproduction's precision and become adequate.

Regarding the $\Delta \alpha$ model (3) one can say that all coefficients of the polynomial model are significant. The strongest influences are the ones of the first order terms: the punch radius,
$\mathrm{R}$, the bend angle, $\alpha_{0}$, and the band thickness, $\mathrm{g}$. It can be observed also the strong influence of the second order terms, respectively, $\alpha_{0}$ and $r$, pointed out by the high curvature of answering surfaces, as seen in Fig. 3. Conclusively, one can say that the determined statistical model, allows a more accurate determination of springback angle for different values of the considered parameters. The model also allows to study the influence of these parameters on springback behaviour.

\section{CONCLUSIONS}

Few relevant conclusions, concerning the results obtained from the above experiments, important for industrial applications and theoretical considerations, can be deducted:

- it is very important to know the influence of the springback on parts, because the final shape of the component depends on it. This factor becomes even more important when the component has closer tolerances.

- the springback is influenced by punch radius, die and punch angle and also material thickness.

- under the same conditions, the springback for the parts with smaller thickness is greater than the parts with greater thickness.

- $\quad$ using the experimental results of the current work, an empirical equation was found. This equation predicts the value of the springback angle with accuracy by $1.36 \%$ average error compared to experimental results.

It was also emphasized the influence of the three considered factors on $\Delta \alpha$ characteristics, making possible the optimization of some parameters such as punch radius, $r$, and $\mathrm{V}$-die bending angle, $\alpha_{\mathrm{D}}$.

\section{REFERENCES}

[1] C. Ciocârdia, Fl. Drăgănescu, Gh. Sindilă, C. Ciocârdia-Carp, and C. Pârvu Tehnologia Presării la Rece, Editura Didactică şi Pedagogică, R.A., Bucureşti - pp. 154-160, 1991.

[2] V.P. Romanovski, Ştanţarea şi matriţarea la rece, Editura tehnică, Bucureşti, 114-121, 1970.

[3] G.E.P. Box, K.B. Wilson, On the experimental attainment of Optimum Condition Royal stat. Soc. B13.1 1951.

[4] Fl. Drăgănescu, and D. Manolache, Matriță dinamometrică pentru modelarea statistică a caracteristicilor îndoirii pieselor în formă de V, Deformări plastice vol. 2 (1995), nr. 2(4), pag. 9 14. Lucrările celei de-a V-a Conferințe Naţionale de Tehnologii şi Utilaje pentru Prelucrarea Materialelor prin Deformare Plastică, Sibiu - România, pp. 9-14, 17-18 nov. 1995. 